\title{
EL PAPEL DEL ESTADO EN LOS MOVIMIENTOS INMIGRATORIOS DE POBLACIÓN DE ORIGEN ANDINO A ESPAÑA EN LOS ÚLTIMOS QUINCE AÑOS
}

\author{
Lucía Pérez García
}

http://dx.doi.org/10.5209/rev_NOMA.2014.v43.n3.49285

\begin{abstract}
Resumen.- Se presenta una descripción cuantitativa de la importancia de las mujeres y personas de origen andino en España, y sus variaciones, sobre todo, desde la década del 2000 hasta la actualidad; destacando el colectivo nacional boliviano como más feminizado y presentando las menores variaciones en el total de población. A partir de tales datos se continúa exponiendo la relación entre los procesos inmigratorios en España, el caso concreto de mujeres de la Región andina, con la estructura del mercado laboral español y distintos mecanismos políticos cómo los Procesos de Regularización, Sistemas de Cuotas, Convenios Bilaterales, imposición del Visado y Políticas de Retorno y Nacionalización, que han incentivado tales procesos migratorios y que condicionarán y determinarán las posiciones sociales de estas mujeres.
\end{abstract}

Palabras clave.- mujeres inmigrantes; Región andina; políticas migratorias; mercado laboral

Abstract.- This paper shows a quantitative's importance description of women and people of andean origin in Spain and its variations especially from the 2000s to the present; the Bolivian national collective is highlighted as the more feminized and the one presenting the smallest variations in relation to the totality of population

Starting from these data the relationship between immigration processes in Spain with the case of women in the Andean Region, and the structure of Spanish labor market as well as its relationship with different policy mechanisms as Regularization Processes, Quota System, Bilateral Agreements, Visa imposition, Return and Naturalization Policies, which have encouraged such migration processes and that will shape and define the social status of these women.

Keywords.- inmigrants women; Andean Region; Inmigration Policy; Laboral Market 


\section{Introducción}

Como ha sido indicado por diversos/as autores/ras España se convierte en "país de inmigración" en la década de los años 80 (IOE, 1987; Arango, 1999; Cachón, 2002; Izquierdo, 1996; Gil Araujo, 2006, entre otras/os). Con ello, se distinguen distintas etapas en los movimientos migratorios internacionales hacia el territorio español, que se diferencian en relación al volumen de inmigrantes. En una primera etapa, los extranjeros provenían de los países de Europa occidental, que se conformaban por grupos de turistas que obtenían un permiso de estancia temporal. Cuando éste expedía podían permanecer en el país sin significar delito ni ilegalidad (Cachón, 2002; Arellano, 2004). De hecho, el proceso de regularización de 1985/1986 se realizó con el objetivo de que los extranjeros europeos obtuvieran documentación de estancia en el país (Izquierdo, 1996). Esta realidad comenzó a cambiar con la inmigración procedente de África, mayoritariamente, de Marruecos, seguida de Guinea Ecuatorial, Latinoamérica y Asia, mayoritariamente filipina, entre los años 70 y 90. La década del 2000 se caracteriza por la diversificación de orígenes nacionales; un cambio de las características de los inmigrantes, a través, de la reagrupación familiar y la aparición de la segunda generación (Cachón, 2002), y la consolidación de España como país inmigrante. Esta evolución se muestra en el número de empadronamientos, a nivel nacional, en el periodo 1998 a 2012 (de 637.985 personas empadronadas en 1998 se pasa a 5.736 .258 en 2012), y los resultados del Censo de Población y Vivienda de 2011, del que se extrae que entre 2001-2011 la población extranjera se incrementa en casi 3, 7 millones de personas, con un total de 5.252.473 no españoles (aunque nacidos en el extranjero representan 6.307.277, de los que 1.439.657 tienen nacionalidad española y 4.867 .620 no española). Al mismo tiempo, estos resultados muestran la importancia de la población latinoamericana (América del Sur, Central o Caribe) que asciende a 2.349.502 (de los que 812.762 tienen la nacionalidad española), seguida de nacidos en un Estado miembro de Unión Europea sumando 2.134.285, y nacidos en África con un total de 1.070.482 (Censo de Población y Vivienda, 2011).

El Padrón Municipal Nacional para el 1 de Enero de 2013 contabiliza 5.520.133 extranjeros en España, de los que 2.677.220 son mujeres. Del total, 1.217.733, proceden de la región de América del Sur, destacando Ecuador (247.266), Colombia (221.929) y Bolivia (163.553). 


\begin{tabular}{|c|c|}
\hline AÑO & $\begin{array}{c}\text { Total de } \\
\text { población }\end{array}$ \\
\hline 1998 & 637.085 \\
\hline 1999 & 748.954 \\
\hline 2000 & 923.879 \\
\hline 2001 & 1.370 .657 \\
\hline 2002 & 1.977 .946 \\
\hline 2003 & 2.664 .168 \\
\hline 2004 & 3.034 .326 \\
\hline 2005 & 3.730 .610 \\
\hline 2006 & 4.144 .166 \\
\hline 2007 & 4.519 .554 \\
\hline 2008 & 5.268 .762 \\
\hline 2009 & 5.648 .671 \\
\hline 2010 & 5.747 .734 \\
\hline 2011 & 5.751 .487 \\
\hline 2012 & 5.736 .258 \\
\hline 2013 & 5.520 .133 \\
\hline
\end{tabular}

Tabla 1. Elaboración propia. Total de población extranjera por nacionalidad, sexo y año. Fuente: Padrón Municipal Nacional (INE)

Para el primer trimestre de 2013 el total de Extranjeros con tarjeta de residencia o permiso en vigor en España ascendía a 5.467.955 que, a diferencia de los empadronamientos, van en aumento en los últimos años (OPI, 2013). Para esta fecha se observan diferencias numéricas entre las dos fuentes citadas, en las que el número de empadronamientos es mayor que el de permisos en vigor. Estas diferencias son menores que en años anteriores, en los que destacaban superiores cantidades de personas empadronadas, que población con tarjeta de residencia o permiso en vigor. Entre 2008 hasta el 2012 comienzan a descender el numero de empadronamientos para llegar a esa relativa equivalencia. En el sentido apuntado es necesario anotar la existencia e importancia de personas en situación de "irregularidad o ilegalidad" 
en España, y con ello, la dificultad de obtener el número de población real. Por tanto, los datos en este sentido debemos tomarlos como orientativos ${ }^{1}$.

Los factores que se han destacado por diversos/as autores/ras para el cambio de España en "país de inmigración" son la europeización de España (Ribas, 2000); los cambios políticos y socio-económicos, como el proceso de democratización y crecimiento económico en España; la libre entrada de extranjeros hasta principios de los años 90, como consecuencia de la implementación de la Ley de Extranjería; el cierre de las fronteras por países europeos a migrantes de terceros países ${ }^{2}$; la introducción desde el 1993 del Sistema de Cuota para servicio doméstico y servicio de agricultura; la apertura y promoción de los campos de cultura, información y economía; la proximidad geográfica; una historia colonial común; vínculos culturales-lingüísticos, especialmente con América Latina; efectos de políticas de ajuste y crisis económicas en partes de América Latina y África (Escrivà, 2000). Otras razones que se argumentan, por parte del país de origen, son las políticas de emigración, la situación socio-económica del país, así como la importancia de la conexión entre migración con desarrollo, y la importancia del colonialismo y su legado (Ribas, 2000; Durán, 2011). Además, señalar la maduración de las redes sociales que se relacionan con procesos históricos (Rivera, 2008).

Por otra parte, Gil Araujo (2006) vincula la inmigración con los cambios acaecidos en el sector económico de la estructura del mercado laboral en España, que pasa de un país eminentemente agrícola en 1950 a una etapa de desarrollo industrial en los años 60 , marcada por la crisis energética de principios de los años 70, que fue sustituida por el despegue del sector servicios. Las diferentes recesiones económicas, reconversiones productivas, como la ocurrida entre 1976 a 1985 y el estancamiento en 1994, después de un crecimiento económico entre 1986 y 1991, permitieron cambios sustanciales en la estructura del empleo, con la aparición del desempleo como estructural, y la precarización del empleo a través de la temporalidad y la flexibilidad; la

\footnotetext{
${ }^{1}$ Han existido medidas para incentivar el empadronamiento como el art ${ }^{\circ} 12$ de la Ley
} Orgánica 4/2000, de 11 de enero, sobre derechos y libertades de los extranjeros en España y su integración social, que vincula el derecho de asistencia sanitaria al estar empadronado. Ademas, se incentivó la inscripción en el padrón municipal al contemplarse como prueba de la presencia en España en los procesos de regularización. De otra parte, se establecieron medidas tendentes a la consecución de datos actualizados del padrón con la obligación legal de toda persona extranjera, que no sea residente de larga duración, de confirmar su empadronamiento cada dos años (Ley 14/2003). También se han destacado los empadronamientos ficticios de ciudadanos comunitarios que residen y se empadronan en España, pero que no solicitan la tarjeta de residencia a la que tienen derecho ( $\mathrm{PECl}, 2007$ 2010).

Por último, destaco que los datos que ofrecen el Padrón Municipal Nacional (INE), y el Anuario Estadístico de Inmigración (AEI/OPI) no coinciden en las regiones de referencia, ya que el primero diferencia entre región América del sur y central y, por tanto, los datos se distribuyen en estas categorías, y el segundo, engloba las dos en región latinoamericana.

${ }^{2}$ En los años 70 países como Alemania federal (1973), Francia (1974), Suiza y otros países de Europa Oeste y Central tomaron medidas restrictivas hacia trabajadores de fuera de CEE. La razón que se argumentó fue el estancamiento económico derivado de la crisis del petróleo, pero existieron otras razones como el cambio en la estructura de los grupos minoritarios, ya que hasta ese momento emigraban hombres jóvenes que no iban acompañados de sus familias, por lo que los costos de reproducción los asumían sus países de origen. De otro lado, se señala la exportación de etapas de producción a lugares de producción fuera de las fronteras, junto con la adopción de nuevas tecnologías (IOÉ, 1987) 
extensión de la economía informal y la desregulación y la segmentación del mercado laboral. Otro cambio clave fue la creciente incorporación de las mujeres españolas al mercado de trabajo en los años 80 y 90, principalmente, en las grandes ciudades (Madrid y Barcelona), que unido a la falta de reparto de las tareas domésticas y la ausencia de servicios públicos, provocó un aumento en la demanda de trabajadores/ras para el empleo doméstico y de cuidados que ha sido asumido, principalmente, por mujeres de origen latinoamericano (Gil Araujo, 2006, López y Oso, 2007; Oso, 2007; Paerregard, 2007; Ribas, 2000; Parella, 2002). Ribas (2000) añade el papel de las políticas inmigratorias internacionales, que en el caso de España, contribuyen a una específica dinámica migratoria con el sistema de cuota y el servicio doméstico, y los cambios en los países de origen relacionado con la desintegración del mercado de trabajo. Sassen (2007), por su parte, plantea un análisis del efecto de la política de Estado a países "expulsores" de migración.

\section{Aproximación a los movimientos de población de la Región Andina a España: protagonismo de las mujeres}

Entre las transformaciones ocurridas en los flujos migratorios hacia España en las ultimas tres décadas destaco las protagonizadas por población latinoamericana, y más concretamente andino, que se han caracterizado por su feminización. Estos movimientos poblacionales experimentan un incremento desde la década de los años 80 hasta la actualidad (Escrivá, 1999, 2000, 2003; Herranz, 1996; Gil Araujo, 2006, 2008; Izquierdo, 1996; Martinez y Golías, 2005; Herrera, 2008, 2011; Paerregard, 2007; López y Oso, 2007; Sallé et al., 2009; Hinojosa, 2008, 2010; Bastia, 2012; Arteaga, 2010; Anguiano, 2002, entre otros/as). Herranz (1996) destaca a la población cubana en los años sesenta, constituida principalmente por exiliados políticos. A partir de los años setenta se intensifican otros colectivos como venezolanos, argentinos, colombianos, chilenos, peruanos, y uruguayos, coincidiendo con lo expuesto por Gil Araujo (2008). En esta década destaca la población procedente de Uruguay, Chile y Argentina, debido al exilio político provocado por las dictaduras militares. Durante los años 80 destaca el crecimiento de la inmigración brasileña, así como el aumento de la inmigración procedente de México, Colombia, República Dominicana y Perú (IOE, 1993; Oso, 2007). Los inmigrantes de Sud y Centro América se duplicaron y se fortaleció la presencia de personas de origen colombiano, dominicano y peruano. Después del proceso de regularización de indocumentados de 1991 salieron a la luz muchos inmigrantes llegados a finales de los años 80, como argentinos, dominicanos y peruanos. Por tanto, la presencia de la población latinoamericana en España, en sus inicios, se sucede en la década de los 70 como consecuencia del exilio político. A partir de los años 80 y sobre todo, desde la década de los años 90 , destaca la migración económica y laboral, consolidándose en la década del 2000 (Gil Araujo, 2006, 2008; Anguiano, 2002).

El crecimiento exponencial de población latinoamericana inmigrante en España ha llevado a algunos autores a describirlos como "los preferidos" por el gobierno español (Gil y Domingo, 2007); refiriéndose a los efectos directos e 
indirectos de la política migratoria a partir de 1996, pero especialmente durante el periodo 2000 a 2001 (Izquierdo et al, 2002). Se ha argumentado la existencia de una voluntad política de substitución de las nacionalidades de la migración en España, en las que las corrientes migratorias latinoamericanas, pero también las procedentes de países del Este, habrían sido beneficiadas, cuando no incentivadas, como muestran los resultados de las operaciones de regularización de 2000 y 2001 (Domingo y Martinez, 2005). A partir de esta fecha destacan las poblaciones de origen ecuatoriano y colombiano, para unirse más tarde la de origen boliviano. Se sucede un incremento continuo de población de origen latinoamericano que asciende en 2004 a 1.118 .055 de personas, y alcanzando el punto álgido en 2009 (1.596.394). Para el año 2012 se contabiliza un total de 1.298.189, haciéndose visible el descenso que se observa desde el año 2010.

A nivel cuantitativo se puede mantener lo que se ha denominado como feminización de migraciones o Generización de migraciones (Gregorio Gil, $1_{1998}{ }^{3}$, en territorio español, de población de origen sudamericano. Tal afirmación se acompaña de los datos que muestra la evolución de la población en el periodo de 1998 a 2012 de población extranjera de origen latinoamericano en España según el Padrón Municipal Nacional:

3 Establece diferencia entre Generización de migraciones, refiriéndose a la adopción de perspectiva feminista en el estudio de migraciones que contempla la influencia del género como el principio organizador, y la Feminización de migraciones, que pone el énfasis en el estudio de un sector de la realidad de las mujeres, y da cuenta de una feminización creciente en términos numéricos, cuyas raíces pueden llevar o no un análisis feminista 


\begin{tabular}{|c|c|c|c|c|c|}
\hline & & & & & \\
\hline & Año & Total & Mujeres & Hombres & \\
\hline & 1998 & 81.712 & 47.990 & 33.721 & \\
\hline & 1999 & 96.780 & 57.264 & 39.517 & \\
\hline & 2000 & 135.904 & 80.767 & 55.136 & \\
\hline & 2001 & 353.355 & 196.110 & 157.247 & \\
\hline & 2002 & 641.209 & 347.737 & 293.472 & \\
\hline & 2003 & 937.150 & 502.328 & 434.822 & \\
\hline & 2004 & 1.118 .055 & 598.070 & 519.985 & \\
\hline & 2005 & 1.302 .889 & 695.979 & 606.910 & \\
\hline & 2006 & 1.349 .962 & 725.610 & 624.352 & \\
\hline & 2007 & 1.408 .785 & 761.687 & 647.098 & \\
\hline & 2008 & 1.563 .040 & 841.575 & 721.465 & \\
\hline & 2009 & 1.596 .394 & 861.731 & 734.663 & \\
\hline & 2010 & 1.533 .207 & 835.926 & 697.281 & \\
\hline $\begin{array}{l}\text { Tabla } 2 . \\
\text { propia: población }\end{array}$ & 2011 & 1.426 .380 & 786.566 & 639.814 & \begin{tabular}{lr}
\multicolumn{2}{c}{ Elaboración } \\
extranjera de
\end{tabular} \\
\hline $\begin{array}{l}\text { origen } \\
\text { en }\end{array}$ & 2012 & 1.298 .189 & 721.061 & 577.128 & $\begin{array}{l}\text { latinoamericano } \\
\text { Fuente: Padrón }\end{array}$ \\
\hline
\end{tabular}

Por su parte, los datos de registro o permiso de residencia de población de origen lberoamericano muestran un incremento de población residente en los últimos 16 años (en 1996 se contabilizaba un total de 104.049 y en 2012 un total 1.464.413). Las nacionalidades que destacan a finales de los años 90 son Argentina, Perú, República Dominicana y Cuba. Notándose un mayor protagonismo, en los primeros años de la década del 2000, de las nacionalidades de Ecuador, Perú y República Dominicana (OPI, 2013).

La irrupción de población de origen ecuatoriano, colombiano y boliviano en la década del 2000 provoca el desplazamiento de orígenes nacionales de las últimas décadas, como peruanos, argentinos, etc, para encabezar las nacionalidades más representativas a nivel numérico. En 2002 se incorpora como población destacada la de origen colombiano, incrementándose la población a nivel anual, y colocándose como segundo país en importancia numérica después de Ecuador, desplazando a Perú que había destacado en años anteriores. Argentina también destaca en estos años, que vuelve a incrementar su población en el año 2001, duplicándose cada año hasta el 
2008. Como se puede observar en el año 2005 destaca la población de origen boliviano con un total de 50.738 que se incrementa hasta 124.695 en el 2010 sin dejar de aumentar en los años posteriores hasta $156.882(\mathrm{OPI}, 2013)$. De esta manera, comienza a ocupar el tercer puesto de población de origen latinoamericano con permiso de residencia en territorio español precedida por Colombia y Ecuador. He aquí la importancia de población de Región Andina en España.

\begin{tabular}{|c|c|c|c|c|}
\hline & Total & Mujeres & Hombres & $\begin{array}{l}\text { Nacionalidades destacadas por } \\
\text { número de población }\end{array}$ \\
\hline 1996 & 104.049 & -- & -- & $\begin{array}{l}\text { Argentina (18.246); Perú (18.023); } \\
\text { Rep. Dominicana (17.845) }\end{array}$ \\
\hline 1997 & 112.064 & 69.391 & 37.425 & $\begin{array}{l}\text { Perú (21.233); Rep. Dominicana } \\
\text { (20.381); Argentina (17.188); Cuba } \\
\text { (10.507) }\end{array}$ \\
\hline 1998 & 129.928 & 81.939 & 43.072 & $\begin{array}{l}\text { Perú (24.879); Rep. Dominicana } \\
\text { (24.256); Argentina (17.007); Cuba } \\
\text { (13.214); }\end{array}$ \\
\hline 1999 & 149.298 & 95.009 & 51.152 & $\begin{array}{c}\text { Perú (27.263); Rep Dominicana } \\
\text { (26.854); Cuba (16.556); Colombia } \\
\text { (13.627; Argentina (16.290); Ecuador } \\
\text { (12.933) }\end{array}$ \\
\hline 2000 & 184.720 & 121.674 & 76.302 & $\begin{array}{c}\text { Ecuador (30.878); Perú (27.888); Rep } \\
\text { Dominicana (26.481); Cuba (19.165); } \\
\text { Argentina (16.610) }\end{array}$ \\
\hline 2001 & 283.778 & 162.978 & 119.560 & $\begin{array}{c}\text { Ecuador (84.699); Perú (33.758); Rep } \\
\text { Dominicana (29.314); Cuba (21.467); } \\
\text { Argentina (20.412) }\end{array}$ \\
\hline 2002 & 364.569 & 205.849 & 158.006 & $\begin{array}{l}\text { Ecuador (115.301); Colombia (71.238); } \\
\text { Perú (39.013); Rep Dominicana } \\
\text { (32.412); Argentina (27.937) }\end{array}$ \\
\hline 2003 & 514.485 & 280.163 & 233.955 & $\begin{array}{c}\text { Ecuador (174.289); Colombia } \\
\text { (107.459); Perú (57.593); Argentina } \\
\text { (43.347); Rep. Dominicana (36.654); } \\
\text { Cuba ( 27.323) }\end{array}$ \\
\hline 2004 & 649.122 & 354.134 & 294.799 & $\begin{array}{c}\text { Ecuador (221.549); Colombia } \\
\text { (137.369); Perú (71.245); Argentina } \\
\text { (56.193); República Dominicana } \\
\text { (42.928) }\end{array}$ \\
\hline
\end{tabular}




\begin{tabular}{|c|c|c|c|c|}
\hline 2005 & 986.178 & 535.882 & 450.219 & $\begin{array}{c}\text { Ecuador (357.065); Colombia } \\
\text { (204.348); Perú (82.533); Argentina } \\
\text { (82.412); Rep. Dominicana (50.765); } \\
\text { Bolivia (50.738) }\end{array}$ \\
\hline 2006 & 1.064 .916 & 577.688 & 487.193 & $\begin{array}{c}\text { Ecuador (376.233); Colombia } \\
\text { (225.504); Perú (90.906); Argentina } \\
\text { (86.921); Rep. Dominicana (58.126); } \\
\text { Bolivia (52.587) }\end{array}$ \\
\hline 2007 & 1.215 .351 & 577.688 & 487.193 & $\begin{array}{c}\text { Ecuador (395.808); Colombia } \\
\text { (254.301); Perú (116.202); Argentina ( } \\
\text { 96.055); Rep. Dominicana (70.775); } \\
\text { Bolivia (69.109) }\end{array}$ \\
\hline 2008 & 1.319 .547 & 707.902 & 611.340 & $\begin{array}{c}\text { Ecuador (421.527); Colombia } \\
\text { (274.832); Perú (130.900); Argentina } \\
\text { (97.277); Bolivia (85.427) }\end{array}$ \\
\hline 2009 & 1.442 .849 & 779.733 & 662.822 & $\begin{array}{c}\text { Ecuador (440.304); Colombia } \\
\text { (287.205); Perú (144.620); Bolivia } \\
\text { (117.106): Argentina (103.171) }\end{array}$ \\
\hline 2010 & 1.373 .878 & 758.487 & 615.391 & $\begin{array}{c}\text { Ecuador (398.724); Colombia } \\
\text { (269.687); Perú (138.211); Bolivia } \\
(124.695)\end{array}$ \\
\hline 2011 & 1.456 .391 & $812 . .226$ & 644.165 & $\begin{array}{c}\text { Ecuador (403.864); Colombia } \\
\text { (274.171); Bolivia (150.702); Perú } \\
(140.792)\end{array}$ \\
\hline 2012 & 1.464 .413 & 824.114 & 640.299 & $\begin{array}{c}\text { Ecuador (397.081); Colombia } \\
\text { (273.149); Bolivia (156.882); Perú } \\
(140.664)\end{array}$ \\
\hline
\end{tabular}

Tabla 3: Elaboración propia. Datos Total de población lberoamérica con Tarjeta de residencia o permiso en vigor. Fuente: Observatorio Permanente de la Inmigración/Anuario Estadístico de Inmigración.

Los movimientos de población andinos a España se caracterizan por su alta feminización. Tal afirmación se corrobora tanto con la explotación estadística como con los estudios que han abordado esta realidad. También se caracteriza por tratarse de una migración económica y laboral, que se ha vinculado con momentos de crisis en los lugares de origen, como la crisis financiera (de la dolarización) ecuatoriana del año 2000, la extensión de violencia en Colombia, el colapso boliviano durante el segundo gobierno de Goni, el ajuste peruano con Fujimori. Además, se referencian otras causas socio-económicas como las reformas de la liberalización de sus economías, la flexibilización del mercado laboral, el desmonte del sistema de protección, la privatización de empresas 
públicas y la reducción del Estado en las últimas dos décadas del siglo $\mathrm{XX}$ (Bonilla, 2008). Además, de venir marcada por los mercados laborales y Estados de recepción, y como un patrón internacional que se vincula a la nueva división del trabajo internacional y a la nueva economía capitalista.

Los años de crisis financiera y económica y su impacto en el mercado laboral en España coinciden con un descenso del total de población de origen andino, sobre todo, a partir de 2009: Ecuador de 440.304 pasan a 398.724; Colombia de 287.205 desciende a 269.687. En 2010, vuelve a aumentar el total de población; en 2011 Ecuador muestra 403.864 personas y Colombia 274.171. Cantidades que descienden en 2012 para el caso de Ecuador a 397.081 y Colombia a 273.149. De otra parte, la población boliviana en territorio español desplaza a estas fechas a orígenes nacionales que se habían consolidado como colectivos más relevantes, por el incremento de población de origen boliviano en la mitad de la década del 2000. Según el Padrón Municipal Nacional para el 1 enero de 2012 había un total de 309.777 ecuatorianos/as, 245. 835 colombianos/as, 180.681 bolivianos/as; para 1 de enero de 2013: 286.964 ecuatorianos/as; 232.551 colombianos/as; 164.360 bolivianos/as, observando que el descenso de población continua. Aunque la población de origen boliviano ha sido la que menos ha descendido en estos años; alcanzando en el año 2008 el mayor volumen de población (242.496, 106.839 $\mathrm{H}$ y 135. $657 \mathrm{M})$. En el año 2009 se observa un descenso del total de población llegando a $230.703(100.489 \mathrm{H}$ y $130.214 \mathrm{M})$, pasando a $213.169(90.948 \mathrm{H}$ y $122.221 \mathrm{M})$ en el año 2010; a $199.080(83.251 \mathrm{H}$ y $115.829 \mathrm{M})$ para el año 2011, y para el 2012 un total de $186.018(76.862 \mathrm{H}$ y $109.156 \mathrm{M})$.

Si se observan los datos de certificados o tarjetas de residencia de población boliviana encontramos un contraste numérico respecto a los datos del Padrón Municipal Nacional. En este sentido, se observa una evolución al alza de personas con tarjeta o permiso de residencia desde el año 2001, que se contrasta con los datos ofrecidos por el número de empadronamientos a nivel nacional. Para el 2005 se registra un aumento porcentual del 343,47\%. Así, en 2008, se asciende a 85.427 personas; en 2009, 117.106; en 2010, 118.273; 2011, 150.702 y en el año 2012, 157.215 (OPI/AEI, 2013). Como se puede observar los datos que se ofrecen de una fuente a otra no coinciden, ya que los requisitos para empadronarse son menos rígidos que el obtener el permiso de residencia por el gobierno español; hecho que coloca en la clandestinidad e irregularidad administrativa a un numero importante de población ${ }^{4}$.

Además, la población de origen boliviano se presenta como la más feminizada, tanto en los resultados del Padrón Municipal Nacional como en el registro de tarjeta de residencia o de permiso en vigor. Se observa como el número de mujeres es mayor que el de hombres, desde los primeros años en los que encontramos datos registrados (INE, 2013; OPI, 2013).

Esta emigración de población boliviana se ha explicado por la situación de inestabilidad en el país, el último proceso de Regularización o Normalización en

4 Se ha hablado del carácter marcadamente irregular a nivel administrativo de población boliviana en España. Gil Araujo (2008): "destacar la persistencia de una gran proporción de irregularidad en el caso de los brasileros, bolivianos, argentinos, uruguayos y venezolanos, después de un proceso de normalización de 2005"(Gil Araujo, 2008:204). Se debe destacar, también, las deportaciones masivas de población boliviana desde el año 2007 (Almazora, 2011). 
España, y el anuncio de la restricción del visado en 2004 (Bastia, 2007, 2011). Además, se argumenta la importancia de la crisis Argentina a finales del año 2000, y los atentados del 11 de septiembre a las Torres gemelas en Nueva York, que endureció las políticas migratorias; así como, el aumento de la demanda de trabajo en el sector de trabajo doméstico y servicio (Hinojosa, 2008, 2010; Bastia, 2011, 2012). Esta intensificación sigue en aumento hasta el 2007, que se hace realidad la restricción del visado a la población boliviana en el Espacio Schengen. Aunque los efectos de la crisis económica en España, desde el año 2008, se han establecido como desencadenantes del retorno de población boliviana. Este se ha relacionado con los efectos en las condiciones de trabajo y a la capacidad de negociación, el aumento de la vulnerabilidad laboral, el miedo de perder a los hijos o estar enferma (Bastia, 2007, 2011). 


\section{El mercado de trabajo regulado español, Procesos de Regularización, Sistemas de Cuotas, Convenios Bilaterales, imposición del Visado y Políticas de Retorno y Nacionalización}

El Estado español se ha mostrado incentivador o desincentivador de la migración latinoamericana y andina en España, es decir, ha sido impulsor de inmigración cuando las circunstancias de despegue económico ha necesitado de mano de obra y la ha contraído cuando esas mismas circunstancias menguan o existen criterios de seguridad, control nacional y europeo. Para ello, ha puesto en marcha diferentes mecanismos, sobre todo, desde la década de los años 90 hasta la actualidad, como las diferentes regularizaciones de población extranjera sirviendo de elemento "Ilamada" que permitió el sistema de entrada y un posterior reconocimiento; el Sistema de Cuotas; los Acuerdos Bilaterales de contratación de trabajadores en origen, firmados con los gobiernos protagonistas de mayores flujos migratorios, y los Programas de Reclutamiento de Trabajadores Temporales (referidos a los trabajos manuales o de baja cualificación); las Políticas de Visado de Corta estancia y Visados para otras situaciones, y las Políticas de retorno y nacionalización. De esta manera, la inmigración de población extranjera y andina, especialmente de mujeres, se ha favorecido en los últimos 15 años.

Estos flujos se inscriben en un contexto de globalización e internacionalización de la fuerza laboral que tomó fuerza a lo largo de la segunda mitad del siglo $X X$, y en lo que llevamos de siglo XXI, que instauró la transferencia de cargas reproductivas de las mujeres y Estados de las "naciones centrales", centradas en tareas domésticas y de cuidado, a mujeres procedentes de otros países (Sallé et al, 2009). Junto a las actividades económicas que no son ocupadas por la población nativa (agricultura, hostelería) y aquellas en las que por las circunstancias de crecimiento del país de recepción necesitan de abundante mano de obra, en este caso masculina (construcción), como ha sucedido en España (Cachón 2009; Pajares 2010; Veira, et al, 2011; Grande et al, 2009). La situación de crisis económica en Europa, con un calado especial en España, afecta directamente a las estrategias de supervivencia de mujeres extranjeras y a su movilidad social (Juliano, 2012).

Entre las diferentes teorías que han explicado la inserción e incorporación de población extranjera en países "Centrales" son la teoría "Mercado laboral dual" (Piore, 1979) o "Segmentación de mercados", a través de la generación de sectores de empleo secundarios caracterizados por la segregación sectorial y ocupacional por sexos y etnias (Cachón, 1997, 2002, 2009; Veira ett al, 2011; Sallé et al, 2009) que enfatiza el papel del Estado, por medio de las normas y prácticas administrativas, que crean un "marco institucional discriminatorio" (Cachón, 1997, 2009). A modo de ejemplo, mediante las restricciones en el acceso a los permisos de residencia y trabajo, limitaciones de los mismos a determinadas actividades, al menos, de modo inicial, o dificultades en las homologaciones de los títulos académicos (Cachón 2009). Otros enfoques teóricos son la Teoría doméstica de supervivencia, el "Hogar transnacional" como resultado de estrategia de grupos domésticos (señalado por Escrivá, 2000 y Gregorio Gil, 1998 respectivamente para el caso de España) y el Enfoque Interseccional de género, que argumenta que las mujeres se enfrentan 
a desventajas múltiples y superpuestas en términos de género, étnica y clase social (Oso y Parella, 2012).

Las características del mercado laboral español afectan a los flujos migratorios y a las posiciones que adquieren las mujeres extranjeras, y con ello, las mujeres de origen andino, como resultado de la situación de desigualdad y desventaja social provocada tanto por las condiciones laborales, la idiosincrasia del sector laboral en el que mayoritariamente se ubican, el trabajo doméstico y de cuidados, y la misma indefensión jurídica en que se encuentran por ocuparse en sectores de economía sumergida y desregulados. Aunque de otra parte, se resuelven como posibles espacios de empoderamiento y autonomía para aquellas mujeres que se han incorporado al mercado de trabajo a través de la migración y permiten que, bajo el cumplimiento de algunas condiciones, se pueda hablar de grados de "deseabilidad" de mujeres inmigrantes hacia la ocupación. Así, las mujeres de migración reciente y sin permiso de residencia, con bajo nivel de estudios o no los tienen convalidados, que tienen contactos y dominan el idioma castellano tienden a trabajar como empleadas del hogar (Alos, 2012) y a "huir" del trabajo en la agricultura. Por su parte, aquellas cuya situación documental está en regla y ya tienen una cierta experiencia laboral en España son más propensas a emplearse en los servicios de hostelería (Veira et al, 2011). Es señalado las diferencias entre la población masculina y femenina en los patrones de inserción laboral (Del Rio y Alonso-Villar, 2010; Parella, 2003) que configura una concentración y segregación por género, muy relacionado con roles tradicionales adscritos (como los servicios de proximidad para mujeres y construcción para hombres). A ésta se añade la concentración y segmentación étnica, que da lugar a la etnoestratificación y escasa movilidad ocupacional, muy relacionado con la importancia del lugar de procedencia y la nacionalidad (Oso Casas, 2007; Grande et al, 2013; Cachón, 1997; Sallé et al, 2009). En esta realidad se ha resaltado la importancia de economía informal en España, que permite la incorporación laboral en situación irregular y aumenta la segmentación étnica y de género (Veira et al., 2011; Baldwin-Edwards, 1999) y el papel de "complementariedad" de la población extranjera con respecto a la autóctona (Gil y Domingo, 2007). Una complementariedad que resaltará el PECl 2007-2010 en su Introducción:"la incorporación de inmigrantes al mercado de trabajo se ha demostrado compatible y complementaria con la mejora del nivel del empleo de los españoles". A ésta se añaden las redes sociales como mecanismo de retroalimentación en términos de etnoestratificación ("nichos étnicos") (Veira,et al, 2011).

Oso (1998) fija en los años 90 el protagonismo de mujeres en la inmigración latinoamericana con fines laborales a España (60\% en 1995). Así destaca a las nacionales de Ecuador (61\%), Colombia (65\%), Perú (64\%), y República dominicana (86\%), que se ocupaban en servicios, fundamentalmente. Entre 1993 a 1997 la crisis económica afectó al sector de la construcción, por lo que en las grandes ciudades, como Madrid, el mercado de trabajo fue más favorable a la inmigración femenina que a la masculina, que ofreció el hueco para la migración de mujeres pioneras en las cadenas migratorias (Oso, 1998). A mediados de los años 80 y principios de los años 90, se desarrolló una primera corriente migratoria de mujeres dominicanas que se insertaron en el mercado de trabajo como empleadas del hogar (Gregorio, 1998; Herranz, 1996) y de mujeres de origen peruano que se incorporaron en el servicio 
doméstico o como cuidadoras de enfermos y ancianos, empresas de limpieza, mensajería, comercio y restauración (Escrivá, 1999). Siguiendo a Oso (2007) la demanda de mujeres extranjeras que se desarrolló en España (años 80 y 90) fue fundamentalmente hacia el servicio doméstico interno, que cumplía con facilitar una vivienda y aumentar la capacidad de ahorro, como "trampolín o situación temporal" hacia otra modalidad de empleo y como mantenimiento de hogares transnacionales, como por ejemplo, las mujeres de origen dominicano (Oso, 2002). También como "camuflaje" de la situación de irregularidad, ya que, en esas fechas, fue característica la entrada como turista por un periodo de tres meses y la permanencia posterior en situación de irregularidad sobrevenida (Oso, 2007) ${ }^{5}$. Posteriormente, a finales de los años 90, se desarrolló la migración laboral de mujeres ecuatorianas (IOÉ, 2001, Gioconda et al, 2005; Pedone, 2004) y colombianas (Restrepo, 1997, 2006). Para el quinquenio de 2000-2005 se amplían los perfiles y se "masifica" la población de origen ecuatoriano, colombiano, y boliviano, sobre todo, desde el año 2005 (INE, 2013; OPI, 2013).

Desde el año 2001 sucede cierto proceso de masculinización de mano de obra o de equilibrio entre los sexos (Oso, 2007; Gil y Domingo, 2007), aunque la población femenina continúa siendo mayoritaria, y un empeoramiento de nivel educativo medio (niveles de enseñanza secundaria y más bajos). Así, en la década del 2000 la personas en proceso migratorio de origen latinoamericano, especialmente andino, se encontraron ocupados, principalmente, en "tres grandes nichos de actividad: a) en aquellos sectores y puestos no preferidos por los españoles por su dureza, bajo salario y/o nulo prestigio social, b) en el sector comercial étnico o generado por la propia llegada de inmigrantes extranjeros c) sustituyendo a las mujeres españolas, cada vez más incorporadas en el mercado de trabajo, en las tareas domésticas y de cuidado de niños y ancianos. Unas tareas que antes efectuaban las mujeres autóctonas "en un contexto de desigual distribución sexual de las tareas domésticas y de débil desarrollo del Estado de bienestar en España" (Gil y Domingo, 2006: 449). Pero, a pesar de estas realidades, las mujeres de la región andina (Ecuador, Colombia y Bolivia) presentan las tasas de actividad y empleo más elevadas, los mayores niveles de concentración sectorial y posiciones muy marcadas en los niveles más bajos de la escala laboral. Su importancia en el sector de actividades en los hogares es mayoritaria ${ }^{6}$, junto con las actividades

5 Esta práctica se ralentizó con la instauración del visado para Ecuador y Colombia, aunque la población originaria de Bolivia la continuó hasta que se le instauró la necesidad de visado en el año 2007

6 Los factores que han explicado la concentración de mujeres de origen latinoamericano en los servicio de proximidad (servicio doméstico y cuidados, fundamentalmente) (Parella, 2002) son la estructura del mercado laboral español, así como el papel de las redes sociales; el mercado de trabajo "pseudo-interno", es decir, el que se conforma mediante la implantación de población inmigrante en estas ocupaciones y que, a través de cierto traspaso de información y recursos entre estos "colectivos", excluye de estas ocupaciones a la población nativa (Martinez Veija,1999). Junto a la incapacidad de las familias de gestionar las necesidades de la vida cotidiana (Portes y Börock (1992), citado en Parella Rubio (2002); los cambios en las relaciones familiares y la incorporación de la mujer española al mercado laboral; la inexistencia de ayudas públicas para conciliar la vida laboral y las tareas domésticas (Estado de bienestar débil); la desaparición de la figura tradicional de la "emigrante doméstica interna" ("la chica del pueblo"); el hecho de que no se ha dado un reparto equitativo entre las parejas a la hora de realizar el trabajo doméstico de cuidado personal (Oso Casas, 1998, 2007). Así como el progresivo 
inmobiliarias y de servicios empresariales (Sallé, et al, 2009). En gran medida, se ha explicado por el papel que asume la migración femenina más reciente, que actúa como sustitutoria de las anteriores, para el caso de ecuatorianas, colombianas y más actualmente, bolivianas, acentuándose las prácticas discriminatorias y las relaciones simbólicas de dominación de clase y étnia (Catarino y Oso, 2000; Oso, 2007).

La invisibilidad, las propias condiciones laborales y la falta de reconocimiento social son hechos endógenos al sector de servicios de proximidad (Parella, 2002; Mestre i Mestre, 2002), pero, además, las mujeres inmigrantes ven aumentar la vulnerabilidad con las dificultades en la obtención de permisos de trabajo y el grado de ciudadanía. Se han sucedido cambios en la regulación laboral del sector de trabajo doméstico, que se describía como un régimen especial flexible basado en la confianza entre empleada y empleador, y la legitimación del contrato verbal, entre otras características. Realidad que se ha pretendido modificar con el Real Decreto 1620/2011 de la Regulación laboral del Servicio del hogar familiar. Esta realidad ha servido como marco para la organización política de sujetos afectados, en su mayoría población femenina migrante, que han creado Sindicatos de trabajadoras domésticas en varios espacios geográficos españoles, a modo de ejemplo, SEDEOAK (Madrid) y Sindihogar (Barcelona).

Por algunos estudios se ha destacado un cierto movimiento laboral ascendente de mujeres latinoamericanas como consecuencia de la reagrupación de varones (Escrivá, 2003), de convertirse en empresarias o el autoempleo (Oso, 2004). Y el salto de empleada de hogar interna a externa 0 por horas (Oso, 2007). Un mayor asentamiento familiar en destino y mantener menos vínculos transnacionales se traduce en una mejor movilidad ascendente. Aunque se afirma que las mujeres presentan un mayor descenso ocupacional en la primera trayectoria y una menor movilidad ascendente en la segunda porque se enfrentan a desventajas múltiples y superpuestas, debido a su concentración en ocupaciones inferiores (servicio domestico, limpieza y cuidados), y el menor reconocimiento a su capital humano en destino (Grande, et al., 2013).

Apunta Alos (2012) en un artículo, que sintetiza resultados de un estudio más amplio, que los efectos de la crisis económica han afectado no sólo a las trayectorias laborales, y por tanto, a las posibilidades de movilidad ascendente y mejora de condiciones de vida, sino que la tasa de empleo ha disminuido y la tasa de desempleo se triplicó para el periodo 2007 a 2012. Con la consiguiente vuelta a trabajos informales y a la economía sumergida, y con ello, la situación de vulnerable irregularidad administrativa. Pero la población femenina ocupada, mayoritariamente, en el sector de empleadas del hogar no se han visto afectadas de la misma manera, ya que en los años de 2008, 2009, 2010, de fuerte recesión, no ha perdido efectivos (Martínez, 2011). A esto añadir el empeoramiento de las condiciones de las mujeres extranjeras que señala Juliano (2012): "obligadas a rebajar expectativas y aceptar peores condiciones

envejecimiento de la población en España, y la falta de cobertura institucional para el cuidado de personas dependientes (Martinez Buján, 2011); diferentes factores relacionados con el estatus de la mujer en los países de origen (Escrivá, 2000) y la potencialidad que ostentan las inmigrantes latinoamericanas por compartir la lengua española (Gil y Domingo, 2006; Veira, Staneck y Cachón, 2011). 
laborales. Además, ha castigado duramente los intentos de organizarse como trabajadoras autónomas, por la falta de créditos y la disminución de las ventas en los pequeños negocios. Por otra parte, los recortes en las prestaciones sociales cargan sus hombros la financiación de gastos escolares y sanitarios que anteriormente podían cubrir mediante Servicios Sociales, becas y otras ayudas" (Juliano, 2012:534).

La descripción del impacto de la estructura del mercado de trabajo español en la inmigración de mujeres de origen andino se acompaña de otras medidas "impulsores de inmigración" por los diferentes gobiernos españoles, como ha sido el caso de los Procesos de Regularización Colectiva a Extranjeros/as ${ }^{7}$, que han puesto en evidencia la realidad migratoria en España y la rigidez establecida para obtener el estatuto de ciudadano/a que chocaba con la demanda del mercado de trabajo. Desde mediados de los años 80 se han realizado seis procesos de regularización: en 1985-1986, dirigido a todos los inmigrantes insuficientemente documentados, y fueron casi 40.000 las peticiones presentadas (Izquierdo, 1996). En 1991: Regularización extraordinaria de trabajadores extracomunitarios. En la que se otorgó la concesión de permisos a 112.000 extranjeros que hasta entonces estaban en situación irregular, entre ellos a 108.000 trabajadores irregulares $^{8}$. En el año 2000: la Regularización extraordinaria (ligada a LO 4/2000) pretendía legalizar la situación de casi 140.000 extranjeros (Aja, 2006). En 2001, la aprobación de la LO 8/2000 incluyó una especie de repesca de la anterior (prevista en Disposición Transitoria Cuarta) por el RD 142/2001. En la que se preveía la revisión de las solicitudes denegadas por la regularización anterior admitiendo las de quienes se encontraban en España en el momento de su entrada en vigor. En el primer caso, como consecuencia de los acuerdos alcanzados entre Delegación de gobierno de Barcelona y los sindicatos, con la participación de Cáritas y la Cruz Roja, por las presiones ejercidas por los encierros en iglesias, que se produjeron en Barcelona y se extendieron a otras ciudades en los primeros meses de 2001, para protestar contra las insuficiencias de la primera regularización y que significaron, en la práctica, una regularización mediante la aplicación anticipada de los instrumentos de los artículos 41 del futuro reglamento de la Ley (el arraigo, los motivos humanitarios y las circunstancias extraordinarias). La Normalización del año 2005, contenida en la Disposición $3^{\text {a }}$ del RD 2393/2004, 30 de diciembre, que contempló el arraigo, aunque para evitar nuevos inmigrantes irregulares se exigió una estancia en España al menos de seis meses, que se podía probar mediante el empadronamiento en el Ayuntamiento (Aja, 2006). En esta fueron presentadas 691.655 solicitudes de autorización de residencia temporal y trabajo por cuenta ajena, el 59\% correspondientes a trabajadores extranjeros y $41 \%$ a trabajadoras extranjeras. Las nacionalidades principales fueron la ecuatoriana $(20 \%)$, rumana $(17 \%)$, marroquí (13\%), colombiana (8\%) y boliviana (7\%). Se resolvieron

7 Estos se hacen muy relevantes para el caso de bolivianas/os, ya que para el proceso de regularización de 2005 fueron 60.000 las peticiones y se aceptaron 48.000 (en prensa), y el anuncio de necesidad de visado aceleró las llegadas de bolivianas/os a España.

8 Hasta 1992 los trabajadores de origen comunitario se registraban dentro de permisos de trabajo en vigor. En el momento que esta categoría desaparece como tal, se destacan los/as trabajadores/ras el continente africano, concretamente Marruecos, de la Región latinoamericana, siendo la Argentina para el Cono Sur, Perú para la región andina y República Dominicana para el Caribe (Izquierdo, 1996). 
favorablemente 577.923 solicitudes, que supusieron 564.487 Afiliaciones o altas en la Seguridad Social (PECI, 2007).

La instauración de la política Sistemas de Cuotas $^{9}$, impulsada por el gobierno español en 1993 (Ribas, 2000; Escrivá, 2000), promovió la inmigración hacia sectores de actividad menos cubiertos por nacionales. Para el año de su inauguración destacó el servicio doméstico con el $72 \%$, frente al $2 \%$ en agricultura, el $20 \%$ en servicios personales y el $0 \%$ en sector de construcción (Izquierdo, 1996). Este mismo mecanismo se aprobó cada año hasta 1999 y supuso la entrada legal de trabajadores/as extranjeros/as en función de las necesidades de mano de obra del Estado Español, que permitió la regularización de mujeres inmigrantes a través del servicio doméstico entre 1995-1999 (Cachón 1997; Oso, 2007). En este sentido se ha visibilizado como el Estado ha ratificado lo que el mercado ha fijado como campo de posibilidades, ejemplificado a través del contingente de 1995: "establecía que podían entrar solo inmigrantes de aquellos países que el mercado ya había seleccionado preferentemente para determinadas ramas de actividad, y así las preferencias de mercado se transforman en "requisitos o prescripciones en la norma jurídica: se aceptaban (varones) marroquíes para la construcción y (mujeres) dominicanas, peruanas o filipinas para el Servicio Doméstico" (Cachón, 1997:58). Además, se han considerado como una política a medio plazo de regularizaciones encubiertas porque los que se acogían a ella eran inmigrantes en situación irregular (Aja, 2006; Ferrero y López, 2009). Las reformas de la ley orgánica en el año 2000 prohibieron esta práctica y exigieron que los extranjeros que se acogían al contingente estuvieran en sus países de origen (artículo 63 LO 4/2000), pero el gobierno durante 2002 y 2003 reguló toda la llegada a través del contingente. Esto tenía la intención de sustituir el régimen general de llegada de inmigrantes, pero diversas sentencias judiciales se opusieron a la desaparición del sistema general (Aja, 2006).

Este sistema de cuotas cambia con la nueva LO 4/2000 y el plan GRECO, que puso en marcha la firma de Convenios bilaterales para cubrir las necesidades de mano de obra acordes al mercado laboral. Los países objeto venían determinados en función de la importancia del flujo migratorio hacia España, que se "determinará por la realidad migratoria española, las relaciones de nuestro país (históricas, políticas, económicas, proximidad geográfica, etc ) y las características de los países de origen" (GRECO, 2001). Al mismo tiempo se endureció el tratamiento de la inmigración ilegal, ya que el contingente no es la manera de entrada más habitual.

Otro de los mecanismos desarrollados son la firma de Convenios Bilaterales con los países generadores de mayor inmigración, como Marruecos (1999), Colombia (2001), República Dominicana (2001), Ecuador (2001), Rumanía y Polonia (2002), Guinea Bisseau y Bulgaria (2003) para la contratación de sus connacionales, a través de contingentes, en el marco de gestión de la migración (Aja, 2006; Ayuso y Sánchez, 2012; Izquierdo, et al, 2002; Ferrero y López, 2009). En 2004 se planteó la reforma del contingente con objeto de ampliar el número de países y se establecieron los Acuerdos Bilaterales, las declaraciones de intenciones y los documentos conjuntos con países como

9 A partir del año 2000 se comienza a identificar como contrataciones colectivas en origen 
Filipinas, Senegal, El Salvador, Ucrania, Paraguay, Bolivia, Moldavia entre otros. Los Acuerdos regulaban los procedimientos, normas y principios para la contratación de trabajadores incluyendo la preselección, la selección y la formación en el país de origen, además de prever la coordinación de programas de apoyo al retorno voluntario. Se incluyen a Comunidades Autónomas dentro de este procedimiento de reclutamiento.

La contratación de trabajadores temporales se vincula con la definición de circularidad migratoria que se establece en el Primer Foro Global sobre Migración y Desarrollo. Se trata de una forma de movilidad reiterada entre zonas de origen y destino que se aleja de la idea de un asentamiento definitivo. Se explican como instrumentos que no solo responden a las necesidades del país receptor, sino que evitan la descapitalización de países emisores, limitando la fuga de cerebros y fomentando la permanencia de su capital humano. Además, de evitar la inseguridad jurídica y los riesgos de la migración irregular, y el mantenimiento de vínculos familiares, sociales y económicos con sus países de origen (Ferrero y López, 2009). Por su parte, Betresey plantea que éstas construyen un "ordenamiento jerárquico de los grupos y cartografías, a través de marcadas distinciones entre los grupos de trabajadores (nacionalidad, etnia, género, edad, ilegales/seleccionados)" (Betresey, 2012:67). Además, incluye a otros entes institucionales como organismos internacionales, agentes institucionales, élites políticas y económicas locales y nacionales, asociaciones y ONGs (Betresey, 2012).

La política de visados, y con ella, la necesidad de visado de corta duración o Visado Schengen y otro tipo de visados, orquestada por la UE, se ha mostrado como el final del trato preferencial hacia la población de origen latinoamericano. El Visado Schengen se sucedió, en gran medida, por la europeización de la política de control de fronteras que afectaba a permisos y condiciones de acceso al Espacio Schengen (y a España) limitando la movilidad o el flujo de personas a estos países. El visado Schengen fue impuesto a un gran número de países, como ejemplo, República Dominicana, Perú y Cuba (1999), Colombia (2002), Ecuador (2003) y Bolivia (2007). Aunque se afirma que para el caso de Perú y Cuba los flujos fueron constantes hasta la crisis (Ayuso y Sanchez, 2012).

Se observa una relación entre la regularización y el incremento del visado de estancia y residencia $e$ incluso el incremento de nacionalizaciones, especialmente, en el caso de Colombia, Cuba y Perú, cuyas poblaciones llevan más tiempo asentadas en España. Para el caso de Bolivia, el proceso migratorio fue más corto y no dio tiempo a la reagrupación familiar antes de la crisis; como tampoco se podrá beneficiar de un nuevo proceso de regularización colectiva por los presupuestos de la Directiva del Retorno. Se argumenta que ante la política de visados se sucede la movilización de las diásporas, que reclaman la protección de los gobiernos de origen ante la política de restricción de sus derechos y los de la movilidad de sus conciudadanos y la movilización desde origen. Los medios de comunicación, políticos y sociedad en general han desarrollado fuertes sentimientos de solidaridad con sus conciudadanos en el exterior (Ayuso y Sanchez, 2012).

Por último, destacan las Políticas hacia el "retorno" y la adquisición de la nacionalidad, sobre todo, de personas de origen ecuatoriano y boliviano que explican las variaciones de residentes de origen andino en los últimos cinco 
años (más acusado en el caso de Ecuador o Colombia, sobre todo, en 2008 y 2009).

Existen diferentes esferas desde las que se ha contemplado el retorno en años recientes. En el ámbito comunitario se destaca la La Directiva de Retorno de 2008, de 18 julio (UE), y el Fondo Europeo para el retorno (desde el 2008) ${ }^{10}$. En España las políticas públicas que abordan el retorno se ubican en 2003 impulsado por Organización Internacional de Migraciones (OIM), a través del Convenio con el Ministerio de Trabajo e Inmigración (que se aprobó en 2005 por España) y puesto en marcha en 2008. Se configuran dos Programas: el Programa de Retorno Voluntario para Inmigrantes en situación de vulnerabilidad (PREVIE), dirigido a personas que lleven en España más de seis meses y se encuentran en situación de vulnerabilidad social, lo que debe probarse por medio de la presentación de un informe de los Servicios Sociales del Ayuntamiento en el que residen (o en su defecto en una ONG especializada). La voluntariedad del retorno debe ser manifiesta por medio de un impreso de voluntariedad. Un segundo programa, es el Programa de Retorno voluntario con capitalización de las prestaciones por desempleo (APRE), que se elabora con la intención de "incentivar" el retorno de trabajadores extranjeros (López, 2010; Durán, 2011) ${ }^{11}$. También se destaca el papel de los gobiernos de los países de origen hacia sus connacionales, como el caso de Ecuador ${ }^{12}$. En la actualidad, el Estado español diferencia tres tipos de Programas de Retorno voluntario: Retorno voluntario de asistencia social, Retorno voluntario productivo y el Programa de ayudas complementarias al abono acumulado y anticipado de la prestación contributiva por desempleo a trabajadores extranjeros extracomunitarios que retornen voluntariamente a sus países de procedencia (APRE) (Secretaria General de Inmigración y Emigración, 2013). Además del que realiza la población por sus propios medios.

La aplicación de los diferentes programas han supuesto el retorno de 2.350 bolivianas/os, 5.634 ecuatorianas/os y 2.365 colombianas/os para el periodo 2009-2012. En estos totales prevalece un tipo de retorno u otro dependiendo de la nacionalidad de origen, para el caso de población de origen boliviana el Programa con mayor número de personas beneficiadas es el de integración social en el año 2009 (1.044 personas), para la población ecuatoriana el Programa APRE en el año 2009 (1.954 personas) y colombiana el mismo Programa APRE en el año 2009 (802 personas).

10 Decisión 575/2007 aprobado por el Parlamento Europeo y el Consejo Europeo para el período 2008-2013.

11 Plantea la necesidad de ser nacional de país extracomunitario que tiene suscrito con España un Convenio bilateral en materia de Seguridad Social, entre otros requisitos.

12 El gobierno de Ecuador puso en marcha una política migratoria que incluye e invita al retorno de sus connacionales. La Secretaría Nacional del Migrante (SENAMI) es la representación en España (Madrid) y su red de Casas del Ecuador. 
Retorno voluntario por Atención Social (2009-2012)

\begin{tabular}{|l|c|c|c|c|c|}
\hline & $\begin{array}{l}\text { Año } \\
\mathbf{2 0 0 9}\end{array}$ & $\begin{array}{l}\text { Año } \\
\mathbf{2 0 1 0}\end{array}$ & $\begin{array}{l}\text { Año } \\
\mathbf{2 0 1 1}\end{array}$ & $\begin{array}{l}\text { Año } \\
\mathbf{2 0 1 2}\end{array}$ & Totales \\
\hline BOLIVIA & 1.044 & 480 & 331 & 337 & 2.192 \\
\hline $\begin{array}{l}\text { ECUAD } \\
\text { OR }\end{array}$ & 258 & 225 & 275 & 200 & 958 \\
\hline $\begin{array}{l}\text { COLOM } \\
\text { BIA }\end{array}$ & 249 & 115 & 150 & 98 & 612 \\
\hline
\end{tabular}

Retorno voluntario productivo (2010-2012)

\begin{tabular}{|c|c|c|c|c|}
\hline & 2010 & 2011 & 2012 & Totales \\
\hline BOLIVIA & 25 & 29 & 16 & 70 \\
\hline $\begin{array}{c}\text { ECUAD } \\
\text { OR }\end{array}$ & 33 & 24 & 11 & 68 \\
\hline $\begin{array}{c}\text { COLOM } \\
\text { BIA }\end{array}$ & 11 & 17 & 55 & 83 \\
\hline
\end{tabular}

Retorno voluntario APRE (2009-2012)

\begin{tabular}{|c|c|c|c|c|c|}
\hline & 2009 & 2010 & 2011 & 2012 & Totales \\
\hline BOLIVIA & 0 & 0 & 7 & 81 & 88 \\
\hline $\begin{array}{c}\text { ECUAD } \\
\text { OR }\end{array}$ & 1.954 & 1.106 & 1.115 & 433 & 4.608 \\
\hline $\begin{array}{c}\text { COLOM } \\
\text { BIA }\end{array}$ & 802 & 333 & 337 & 198 & 1.670 \\
\hline
\end{tabular}

Tabla 4, 5 y 6: Elaboración propia a partir de datos de Secretaria General de Inmigración y Emigración (17 enero 2013).

La nacionalización interesa por la incidencia en el descenso del total de población inmigrante andina. La política hacia la nacionalización deviene de lo 
amparado en la CE (art ${ }^{-11.1}$ y 11.3), que se amplia en la reforma del Código Civil español por Ley 18/1990, 17 de diciembre, que establece que las personas de nacionalidad de algún país hispanoamericano, junto con nacionalidad filipina, ecuatoguineana, andorrana o aquellas que podían acreditar ser descendientes de la población sefardí expulsada de España en 1492, se benefician de un acceso a la nacionalidad española preferente, en el que se les requiere dos años de residencia legal y continuada, para acceder a los trámites de la naturalización, mientras que a los nacionales de otros países se les demanda constancia de diez años. Ello explica que del total de nacionalizados entre 1991 y 2001, 81.720 correspondieron a personas de origen latinoamericano, lo que representa un $78 \%$ del conjunto de nacionalizaciones otorgadas a extranjeros durante el periodo. Otras medidas que han afectado al aumento de la naturalización han sido la Ley de Memoria Histórica del año 2007, que reconocía la nacionalidad a personas con origen de países de gran emigración española (Venezuela, Argentina y Uruguay). Y los Acuerdos de doble Nacionalidad: Argentina, Bolivia, Chile, Colombia, Costa Rica, Ecuador, Honduras, Nicaragua, Paraguay, Perú, República Dominicana, entre otros, (Ayuso y Sánchez, 2012).

Para los países andinos (Ecuador, Colombia y Bolivia) se destaca el aumento del número de personas nacionalizadas para el periodo 2002-2012, destacando el año 2010 con el mayor número de nacionalizaciones de Ecuador (43.091, de las 25.266 son mujeres), Colombia (23.995, de las 14.729 son mujeres), y Bolivia que destaca el año 2012, con 7.424 de las que 4.877 son mujeres (Secretaría de Inmigración y Emigración, 2012).

A pesar de mostrarse el impacto del retorno y el descenso de población de origen andino, sobre todo ecuatoriano y colombiano, se puede apreciar que el número de nacionalizaciones es mayor que los datos que se presentan del número de personas retornadas. Se ha de tener en cuenta los movimientos migratorios hacia otros punto geográficos y el retorno por propios medios y que se conserve el empadronamiento o el permiso de residencia. Lo que se puede concluir, según los datos, es la permanencia en España de población de origen andino, en el que destaca la poca movilidad geográfica que se observa de la población boliviana.

\section{A modo de conclusión}

Estas actuaciones o mediadas institucionales han servido para facilitar, al mercado de trabajo y grupo empresarial español, el remplazo de trabajadores/as en el momento que lo han necesitado, e instalar una mayor rigidez hacia los flujos migratorios con objeto de controlar, perseguir y sancionar la libre circulación de personas recogidas en los Tratados internacionales. Además, ha incidido en las posiciones de subalternidad de las personas en proceso migratorio, y por tanto, en las posiciones sociales y políticas de las mujeres, así como, en las identidades de la migración afectadas por los "lugares" en los que han sido ubicadas por la estructura socioeconómica y legal de la sociedad de residencia. Esta realidad ha afectado en mayor 
medida a las mujeres de origen andino, en cuanto representan las inmigraciones más recientes. Se las ha presentado como los perfiles más bajos en un contexto de incremento de inmigración desde los años 2000 hasta al actualidad que ha provocado mayor control, persecución e instrumentalización de población femenina migrante en pro de la mayor preocupación de los países europeos, como España, que es su mercado laboral.

\section{Referencias bibliográficas}

AJA, E. (2006), "La evolución de la normativa sobre inmigración", En AJA, E. y ARANGO, J. (Eds.): Veinte años de inmigración en España. Perspectivas jurídica y sociológica (1985-2004), Fundación CIDOB, Barcelona

ALÓS, R. (2012), “Una aproximación a la segregación étnica en España: trayectorias laborales comparadas de la población inmigrante". Revista de Economía Crítica,14, ISNN 2013-5254, Madrid, pp,107-123

ALZAMORA DOMÍNGUEZ, M. A. (2011),"Migración boliviana entre España y Argentina. Vínculos políticos en un nuevo espacio transnacional". Actas del I Congreso Internacional sobre Migraciones en Andalucía (pp. 1215-1223). Instituto de Migraciones, Granada

ANGUIANO TÉLLEZ, M. E. (2002),"Emigración reciente de latinoamericanos a España: trayectorias laborales y movilidad ocupacional". Gaceta laboral, 8(3), Venezuela, pp, 411-424

ARANGO, J. (1999), "Becoming a Country of Immigration at the End of the XXth Century: the Case of Spain", En KING, R.;. LAZARIDIS, G; TSARDANIDIS, C. (Eds.), Eldorado or Fortress? Migration in Southern Europe, Macmillan Press, Londres

ARELLANO MILLÁN, M. J. (2004), "La inserción social de las inmigrantes latinoamericanas en España: migraciones laborales y género". Tesis Doctoral, Fernando Franco, Lorenzo (Dir.), Universidad Complutense de Madrid, Madrid

ARTEAGA, A. M. (2010), "Informe Global: Mujeres Migrantes Andinas: Contexto, políticas y gestión migratoria", Andros Impresores, Santiago de Chile

AYUSO, A. y SÁNCHEZ-MONTIJANO, E. (2012), "Los costes del rechazo: América Latina y Caribe ante las barreras a la entrada en España y UE", En SÁNCHEZ-MONTIJANO, E, VAQUER I FANÉS, J Y VIILUP, E. (Eds.), La política de visados para el siglo XXI. Más allá de la cola del visado, CIDOB, Barcelona

BALDWIN-EDWARDS, M. (1999), "Where Free Markets Reign:Aliens in the Twilight Zone”, En BALDWIN- EDWARDS, M. y ARANGO, J. (Eds.), Inmigrants and the informal Economy Southern Europe, Frank Cass London, Portland, OR

BASTIA, T. (2007), "From Mining to Garment Workshops: Bolivian Migrants in Buenos Aires", Journal of Ethnic and Migration Studies, 33:4, Londres, pp, 655-669, http: //dx.doi.org/10.1080/13691830701265628

- (2011), "Should I stay or Should I go? Return migratio intimes of crises". Journal of International Development Journal International Development, 23, pp,583-595, DOI: $10.1002 / j i d .1794$

(2012), "I am going with or without you: autonomy in Bolivian Transnational Migrations", Gender, Place \& Culture: A Journal of Feminist Geography. Routledge, Taylor \& Francis Group, pp, 160-177, DOI:10.1080/0966369X.2011.649353

BETRISEY NADALI, D. (2012), "Políticas de reclutamiento de trabajadores en España: la construcción social de" emigrantes patriotas" e" inmigrantes responsables", AlBR. Revista de Antropología Iberoamericana, Vol. 7,1, pp, 65-97, Madrid 
BONILLA, A. (2008), "Migraciones Latinoamericanas: Proceso Político, Flujos y Remesas". Ponencia presentada en el Foro de Biarritz 3-4 2008, Francia

CACHÓN RODRIGUEZ, L. (1997), "Segregación sectorial de los inmigrantes en el mercado de trabajo en España", Cuadernos de Relaciones Laborales,10, pp. 49- 73, Madrid

- (2002) "La formación de la 'España inmigrante': mercado y ciudadanía", Revista Española de Sociología, 97, pp. 95-126, Madrid

- (2009) La España inmigrante: marco discriminatorio, mercado de trabajo y política de integración", Anthropos, Barcelona

CATARINO, Ch. y OSO, L. (2000), "La inmigración femenina en Madrid y Lisboa: hacia una etnización del servicio doméstico y las empresas de limpieza", PAPERS. Revista de Sociología, (60), pp, 183-207, Barcelona

\section{CONSTITUCIÓN ESPAÑOLA DE 1978, (Novena Edición 1994,) Arguval, Málaga}

DIARIO OFICIAL DE LA UNIÓN EUROPEA (2007), L 144, 6 de junio, Decisión № 575/2007/CE del Parlamento Europeo y del Consejo, de 23 de mayo de 2007 por la que se establece el Fondo Europeo para el Retorno para el período 2008- 2013 como parte del Programa General "Solidaridad y Gestión de los Flujos Migratorios", Bruselas

DEL RIO, C. y ALONSO-VILLAR, O. (2010), "Gender Segregation in the Spanish Labor Market: An altenrnative Approach", Social Indicators Research, Vol. 98, 2, pp.337-362, Netherlands

DOMINGO VALLS, A. y MARTINEZ, R. B. (2005), "La población latinoamericana censada en España en 2001: un retrato sociodemográfico", Papers de Demografía, (275), pp. 1-34, Barcelona

DURÁN RUÍZ, F. J. (2011), "El retorno voluntario y forzado de los migrantes en el contexto de crisis económica, de la política migratoria común y de al construcción de la Unión Europea". En IV Congreso de la Red Internacional de Migración y Desarrollo. Crisis Global y estrategias migratorias hacia la redefinición de las políticas de movilidad, 18, 19 y 20 de mayo, FLACSO, Quito, Ecuador

ESCRIVÁ CHORDÁ, A. (1999), "Mujeres peruanas del servicio doméstico en Barcelona: trayectorais sociolaborales", Tesis Doctoral, Universitat Autònoma de Barcelona, Barcelona.

- (2000) The position and status of Migrant Women in Spain", En Anthias, and Lazaridis, G (eds): "Gender and Migration in Southern Europe. Women on the move", Oxford, New York,

- (2003) Inmigrantes peruanas en España. Conquistando el espacio laboral extradoméstico". Revista Internacional de Sociología (RIS), Tercera Época, 36, pp. 59-83, Madrid

FERRERO TURRIÓN, R. y LÓPEZ SALA, A. (2009), "Nuevas dinámicas de gestión de las migraciones en España: el caso de los acuerdos bilaterales de trabajadores con países de origen", Revista del Ministerio de Trabajo e Inmigración, (80), pp, 119-131, Madrid.

GIL ARAUJO, S. (2006), "Las argucias de la integración. Construcción nacional y gobierno de lo social a través de las políticas de integración de inmigrantes. Los casos de Cataluña y Madrid". Tesis Doctoral, Universidad Complutense de Madrid, Madrid

- (2008) "Migraciones latinoamericanas hacia el estado español. La reactivación del sistema migratorio transatlántico", En Rodriguez, lleana; Martinez, Josebe (coord), "Postcolonialidades históricas: (in)visibilidades hispanoamericanas/colonialismos ibéricos", ED Anthropos, Barcelona

GIL, F. y DOMINGO, A. (2007), "Inserción laboral de la población latinoamericana inmigrada en España", En Yepez del Castillo, Isabel y Herrera, Gioconda (Edit), Nuevas Migraciones latinoamericanas a Europa. Balance y desafíos. Flacso, Obreal, UCL, UB, pp, 427-452, Quito

GRANDE, R., DEL REY POVEDA, A., y FERNÁNDEZ MACÍAS, F. (2013), "Movilidad Ocupacional de los Inmigrantes en España: entre la etnoestratificación y la mejora ocupacional". XI Congreso Español de Sociología, 10,11 y 12 de Julio, FES, Madrid

GREGORIO GIL, C.(1998), "Migración femenina. Su impacto en las relaciones de género", Ediciones NARCEA, Madrid 
HERRANZ GOMEZ, Y. (1996), "Formas de incorporación laboral de la inmigración latinoamericana en Madrid. Importancia del contexto de recepción", Tesis Doctoral, Universidad Autónoma de Madrid, Madrid

HERRERA MOSQUERA, G. (2008), "Mujeres ecuatorianas en el trabajo doméstico en España. Prácticas y representaciones de Exclusión e Inclusión", En NOVICK, S. (comp.), Las migraciones en América Latina, Catálogos, pp. 73-92, Buenos Aires (Argentina)

Buenos Aires

(2011) "Cuidados Globalizados y desigualdad social", Nueva Sociedad, 233, pp 87-97,

HERRERA, G., CARRILLO, M C. Y TORRES, A. (2005), "La migración ecuatoriana. Transnacionalismo, redes e identidades", FLACSO, Plan Migración Comunicación y Desarrollo, Quito (Ecuador).

HINOJOSA GORDONAVA, A. (2008), "España en el itinerario de Bolivia. Migración transnacional, género y familia en Cochabamba", En NOVICK, S. (comp.), Las migraciones en América Latina, Catálogos, pp. 92-112, Buenos Aires

- (2010) "Buscando la vida. Familias transnacionales en España", Consejo Latinoamericano de Ciencias Sociales-CLACSO, Buenos Aires

INSTITUTO NACIONAL DE ESTADÍSTICA (2011), Censo de Población y Vivienda 2011, Madrid. Disponible: www.ine.es

INSTITUTO NACIONAL DE ESTADÍSTICA (2013), Padrón Municipal Nacional periodo 19982012, Madrid. Disponible: www.ine.es

INSTITUTO NACIONAL DE ESTADÍSTICA (2013), Padrón Continuo. Datos a nivel nacional, Comunidad Autónoma y provincia. Madrid. Disponible: www.ine.es

IOÉ, Colectivo (1987), "Los inmigrantes en España”. Cáritas española, Madrid

- (1993), "Rasgos generales y perfil sociodemografico. Inmigrantes extranjeros en Madrid", vol 1, Comunidad de Madrid, Madrid.

- (2001), "Mujer, inmigración y trabajo", Ministerio de Trabajo y Asuntos Sociales. Secretaría General de Asuntos Sociales. Instituto de Migraciones y Asuntos Sociales, Madrid.

IZQUIERDO ESCRIBANO, A. (1996), "La inmigración inesperada. La población extranjera en España, 1991-1995”. Ed. Trotta, Madrid

IZQUIERDO ESCRIBANO, A.; LÓPEZ DE LERA, L. y MARTÍNEZ BUJÁN, R. (2002), "Los preferidos del siglo XXI: la inmigración latinoamericana en España". En Actas III Congreso Inmigración en España, Vol. 2, pp, 237-250, Granada

JEFATURA DEL ESTADO (1990), LEY 18/1990, de 17 de diciembre, sobre reforma del Código Civil en materia de nacionalidad, BOE num. 302, 18 de diciembre de 1990, Madrid

- (2000) Ley Orgánica 4/2000, de 11 de enero, sobre derechos y libertades de los extranjeros en España y su integración social, Boletín Oficial del Estado, num. 10, de 12 de Enero de 2000, Madrid

- (2003) Ley Orgánica 14/2003, de 20 de noviembre, de Reforma de la Ley Organiza 4/2000, de 11 de Enero, sobre derechos y libertades de los extranjeros en España y su integración social, modificada por la Ley Orgánica 8/2000, Boletín Oficial del Estado, núm. 279, de 21 de noviembre 2003, Madrid

JULIANO CORREGIDO, D. (2012), "Género y trayectorias migratorias en época de crisis". Revista Papers, 97/3, pp.523-540, Barcelona

LÓPEZ DE LERA, L. (2010), "Emigración, inmigración y retorno, tres etapas de un mismo proceso", POLÍGONOS, Revista de Geografía, núm. 20, pp. 9-27, León

LÓPEZ DE LERA, D y OSO CASAS, L. (2007), "La inmigración latinoamericana en España. Tendencias y estado de la cuestión". En, YEPEZ DEL CASTILLO, I y HERRERA, G (eds.), Nuevas migraciones latinoamericanas a Europa. Balances y desafíos, Flacso/ OBREAL /UCL/UB, Quito, Ecuador 
MARTÍNEZ BUJÁN, R. (2011), "La reorganización de los cuidados familiares en un contexto de migración internacional". Cuadernos de Relaciones Laborales, 29, 1, pp. 93-123, Madrid

INEZ BUJÁN, R y GOLÍAS PÉREZ, M. (2005), "La latinoamericanización de la inmigración en España". Cuadernos Geográficos, 36, Universidad de Granada, pp 51-64, Granada

EDWARDS, M Y ARANGO, J, (ed), Inmigrants and the informal Economy Southern Europe. Frank Cass London, Portland, OR.

MEDINA, E.; ERRARTE, A. y VICÉNS, J. (2010), "Inmigración y desempleo en España: impacto de la crisis económica", ICE, Retos Económicos Derivados de la Inmigración Económica en España, 854, pp, 37-48, Madrid.

I MESTRE, R. M. (2002), "DEA EX MACHINA. Trabajadoras Migrantes y negociación de la igualdad en lo domestico (Experiencias de ACUDE-VIMAR: ecuatorianas en Valencia). Cuadernos de Geografía, 72, pp. 191-206, Valencia

MINISTERIO DE TRABAJO Y ASUNTOS SOCIALES ,Plan Estratégico de Ciudadanía e Integración 2007-2010, Madrid

MINISTERIO DE INTERIOR/DELEGACIÓN DEL GOBIERNO PARA LA EXTRANJERÍA Y LA INMIGRACIÓN (2000), Programa Global de regulación y coordinación de la extranjería y la inmigración. Resolución de 17 de abril de 2001 de la Delegación del Gobierno para la Extranjería y la inmigración (BOE), Madrid

MINISTERIO DE TRABAJO E INMIGRACIÓN (2011), Real Decreto 1620/2011, de 14 de noviembre, por el que se regula la relación laboral de carácter especial del servicio del hogar familiar. Boletín Oficial del Estado, núm. 277, de 17 de noviembre de 2011, Madrid

OBSERVATORIO PERMANENTE DE LA INMIGRACIÓN/SECRETARIA DE INMIGRACIÓN E INMIGRACIÓN (2013). "Extranjeros residentes en España. Extranjeros con certificado de registro o tarjeta de residencia en vigor. Ministerio de Empleo y Seguridad Social", Madrid (Consultas realizadas periodo 1996-2013)

- (2004), "El empresariado étnico como una estrategia de movilidad social para las mujeres inmigrantes en España". Instituto de la Mujer, informe inédito de investigación, Madrid.

- (2007) "La inserción laboral de la población latinoamericana en España: El protagonismo de las mujeres", En YEPEZ DEL CASTILLO y HERRERA, G, Nuevas Migraciones latinoamericanas a Europa. Balance y desafíos. Flacso, Obreal, UCL, UB, pp. 453479, Quito.

OSO CASAS, L. y PARELLA RUBIO, S. (2012), "Inmigración, género y Mercado de trabajo: una panorámica de la investigación sobre la inserción Laboral de las mujeres inmigrantes en España", Cuadernos de Relaciones Laborales, 30, 1, pp. 11-44, Madrid

PAERREGARD, K. (2007), "La migración femenina: estrategias de sostenimiento y movilidad social entre peruanos en España y Argentina", Anthropologica, Año XXV, № 25, pp 61-82, Lima

PAJARES, M. (2010), "Inmigración y mercado de trabajo. Informe 2010", Documento del Observatorio permanente de la inmigración, Ministerio de Trabajo e Inmigración, Madrid

PARELLA RUBIO, S. (2002), "La internacionalización de la reproducción. La inserción laboral de la mujer inmigrante en los servicios de proximidad". Tesis Doctoral por Universitat Autónoma de Barcelona, Barcelona

- (2003) "Mujer, inmigrante y trabajadora: la triple discriminación, Anthropos Editorial, Colección Autores, Textos y Temas. Ciencias Sociales, 36, Rubí (Barcelona)

PEDONE, C. (2004), "Tú siempre jalas a los tuyos": cadenas y redes migratorias de las familias ecuatorianas en España. Tesis doctoral, Universidad Autónoma de Barcelona, Barcelona

RESTREPO VÉLEZ, M. O. (1997), "Mujeres colombianas: sujetos históricos en una historia de inmigración, Tesis Doctoral, Universidad Autónoma de Madrid, Madrid

- (2006) "Mujeres colombianas en España. Historias, Inmigración y Refugio. Pontificia Universidad Javeriana $=$ Instituto Pensar, Bogota DC 
SALLÉ ALONSO, M A, MOLPECERES ALVAREZ, L. y ONGIL LOPEZ, M. (2009), "Análisis de la situación laboral de las mujeres inmigrantes: Modalidades de inserción, sectores de ocupación e iniciativas empresariales". Colección Estudios, ㄲo 110 Instituto de la Mujer, Madrid

RIBAS MATEO, N. (2000), "Female Birds of Passage: leaving and settling in Spain", En Anthias, and Lazaridis, G (eds), Gender and Migration in Southern Europe. Women on the move, Oxford, New York,

RIVERA SANCHEZ, L. (2008), Redes, prácticas de interconexión y vínculos sociales en un circuito migratorio transancional", En NOVICK, S. (comp.), Las Migraciones en América Latina,Catálogos, Buenos Aires

SASSEN, S. (2007), "Una Sociología de la globalización”, Katz, Buenos Aires

SECRETARÍA GENERAL DE INMIGRACIÓN Y EMIGRACIÓN (2012), Concesiones de nacionalidad española por residencia, Ministerio de Empleo y Seguridad Social, Madrid

- (2013) Retorno voluntario de atención social, según países y anualidades 2009-2012, Ministerio de Empleo y Seguridad Social, Madrid

Madrid

(2013) Retorno voluntario APRE 2009-2012, Ministerio de Empleo y Seguridad Social,

\section{Social, Madrid}

(2013) Retorno voluntario productivo 2009-2012, Ministerio de Empleo y Seguridad

VEIRA, A; STANEK, M.; CACHÓN, L. (2011), "Los determinantes de la concentración étnica en el mercado laboral español". Revista Internacional de Sociología, (HIS) La inmigración en España: perspectivas innovadoras, MONOGRAFICO n 1, 219-242, Madrid 